\title{
Patient Safety and the Safety Culture
}

\section{Xiuzhu GU*}

Department of Industrial Engineering and Management, Graduate school of Decision Science and Technology, Tokyo Institute of Technology, Tokyo, Japan

\section{What is patient safety?}

Safety is firstly absence of error. Safety, as one aspect of quality, is more than just the absence of errors. It has multiple dimensions, including the following: an outlook that recognizes that health care is complex and risky and that solutions are found in the broader systems context; a set of processes that identify, evaluate, and minimize hazards and are continuously improving, and an outcome that is manifested by fewer medical errors and minimized risk or hazard [1]. For patients, safety is defined as freedom from accidental injury.

\section{What is safety culture?}

Medical mistakes were viewed as individual provider issues, therefore, to avoid punishments; keeping secrets were common in health care. In 1999, "To Err Is Human: Building a Safer Health System" report [2] was published by the U.S. Institute of Medicine. One year later, "An Organization with a Memory" was published by the UK Department of Health [3]. In these two reports, the same things were mentioned that were changing the focus from blaming individuals to organizational learning, designing safety into the system and creating a culture of safety.

A number of definitions have been proposed of safety culture. For instance, Hale [4] defined safety culture as "the attitudes, beliefs and perceptions shared by natural groups as defining norms and values, which determine how they act and react to risks and risk control systems". The rationale behind studying the safety culture of an organization or work unit is its proactive use for risk management. From results of safety culture assessment, it may be able to identify "weak points" in attitudes, norms and practices of the target groups, then to implement an intervention program aiming at improving patient safety before an actual accident taking place. There are three component cultures in safety culture suggested by Reason and Hobbs
[5]: (1) reporting culture - organizational climate in which people are prepared to report their errors; (2) just culture - atmosphere of trust in which people are encouraged, even rewarded, for providing essential safety-related information; and (3) learning culture - willingness and competence needed to draw right conclusions from safety information systems such as the incident reporting system, and the will to implement major reforms when their need is indicated.

\section{What is just culture?}

As mentioned before, organizations changed from blaming individuals to encouraging error reporting and learning. To encouraging reporting, a blame-free culture was proposed by a number of researchers. But persons who made mistakes reporting errors with impunity absolutely are actually difficult in any organization. It was also discussed that whether individuals taking no accountability were really appropriate in health care. Just culture, as part of safety culture, is in between a punitive culture and a blame-free culture, Marx [6] described it as: one that encourages people to raise their hands and say they made a mistake, yet still holds them accountable if they choose behavior that knowingly puts someone at risk.

\section{References}

1. Kenneth WK (1999) VHA's patient safety improvement initiative.

2. Kohn LT, Corrigan JM, Donaldson MS (1999) To err is human: Building a safer health system. Institute of Medicine. National Academy Press, Washington D.C. 1999

3. Donaldson L (2000) An organisation with a memory. Report of an expert group on learning from adverse events in the NHS chaired by the Chief Medical Officer.

4. Hale AR (2000) Culture's confusions. Safety Science 34: 1-14.

5. Reason J, Hobbs A (2003) Managing maintenance error: a practical guide.

6. Marx D (2001) Patient Safety and the "Just Culture": A Primer for Health Care Executives.
*Corresponding author: Xiuzhu Gu, Department of Industrial Engineering and Management, Graduate school of Decision Science and Technology, Tokyo Institute of Technology, W9-55, 2-12-1 Oh-okayama, Meguro-ku, Tokyo 152-8552, Japan, E-mail: xiuzhu.g.aa@m.titech.ac.jp

Received July 26, 2012; Accepted July 28, 2012; Published July 31, 2012

Citation: Xiuzhu GU (2012) Patient Safety and the Safety Culture. Ind Eng Manage 1:e109. doi:10.4172/2169-0316.1000e109

Copyright: (c) 2012 Xiuzhu GU. This is an open-access article distributed unde the terms of the Creative Commons Attribution License, which permits unrestricted use, distribution, and reproduction in any medium, provided the original author and source are credited. 